\title{
Self-Regulated Learning in the Classroom: A Literature Review on the Teacher's Role
}

\author{
Daniel C. Moos and Alyssa Ringdal \\ Department of Education, Gustavus Adolphus College, Mattson Hall, 800 West College Avenue, Saint Peter, MN 56082, USA \\ Correspondence should be addressed to Daniel C. Moos, dmoos@gustavus.edu \\ Received 18 March 2012; Revised 23 May 2012; Accepted 23 May 2012 \\ Academic Editor: Bracha Kramarski \\ Copyright ( 2012 D. C. Moos and A. Ringdal. This is an open access article distributed under the Creative Commons Attribution \\ License, which permits unrestricted use, distribution, and reproduction in any medium, provided the original work is properly \\ cited.

\begin{abstract}
Empirical research has supported the long held assumption that individual differences exist in how students learn. Recent methodological advancements have allowed educational research to examine not only what students learn, but also how they learn. Research has found that active involvement in learning, including setting meaningful goals, selecting appropriate and taskspecific strategies, monitoring motivational levels, and adapting based on feedback are all positively related to learning outcomes. How can teachers support students' development and use of these learning processes? The goal of this paper is to examine research that has used the Self-Regulated Learning (SRL) theory to consider this broad question. Methodological advancements recently used in this field of research, various SRL theoretical frameworks guiding this research, and studies that empirically examined selfregulation with both preservice and inservice teachers are discussed. The paper concludes with the theoretical, methodological, and practical implications of the reviewed studies.
\end{abstract}

\section{Introduction}

Empirical research has supported the long held assumption that individual differences exist in how students learn. Recent methodological advancements have allowed educational research to examine not only what students learn, but also how they learn. Moos and Azevedo, for example, have used a think-aloud protocol to capture the dynamic nature of how individual students use strategies, monitor emerging understanding, and make plans during learning. The think-aloud has provided rich data, as evidenced by the following excerpt from one of their studies [1]. This study provided process data on how students learn about a conceptually complex science topic. The regular font indicates the student's thoughts as she thinks aloud, whereas the italicized font indicates reading from the material during the learning task.

I am going to start with the circulatory system just because I am already there...and I'm just reading the introduction...circulatory system... also known as the cardiovascular system and it deals with the heart. ..it transports oxygen and nutrients and it takes away waste...um, it does stuff with blood and I'm kind of remembering some of this from bio in high school, but not a lot of it.

\section{Reads: The heart and the blood and the blood vessels are the three structural elements and the heart is the engine of the circulatory system, it is divided into four chambers.}

I knew this one, two right and two left. . .the atrium, the ventricle and the left atrium, and the left ventricle...okay start the introduction [of the heart], just kind of scout it out real quick... and there's a section called function of the heart...and it looks like it will give me what I need to know...um...introduction, oh that's just basic stuff that we've been doing...

Reads: Structure of the heart has four chambers...

We did that...

Reads: The atria are also known as auricles. They collect blood that pours in from veins...

So, it looks like the first step is atria in the system and then the veins. 
Though this segment is a small snapshot of the student's learning process for this particular task (see [2] for the complete data), it is clear that she was actively engaged in the learning process. She monitored the relationship between the content and her prior domain knowledge (i.e., "I am kind of remembering some of this from bio in high school"), while also using appropriate strategies. Even within this short learning segment, the student engaged in these monitoring processes and used strategies at multiple points (i.e., "We did that..." and "So, it looks like the first step is atria..."). This student's active engagement was not observed with all the participants in this study, as demonstrated by the following excerpt from another participant who was asked to learn the same material in an identical context as the above student.

I am going to the introduction. . .

Reads: Circulatory system, or cardiovascular system, in humans, the combined function of the heart, blood, and blood vessels to transport oxygen and nutrients to organs and tissues throughout the body and carry away waste products. .

I'm going to take notes...transport oxygen...nutrients...to organs and tissues and carry away waste products.

Reads: Among its vital functions, the circulatory system increases the flow of blood to meet increased energy demands during exercise and regulates body temperature. In addition, when foreign substances or organisms invade the body, the circulatory system swiftly conveys diseasefighting elements of the immune system, such as white blood cells and antibodies to regions under attack...

I'm writing down the structural elements...

Reads: The heart is the engine of the circulatory system. It is divided into four chambers: The right atrium, the right ventricle, the left atrium, and the left ventricle. The walls of the chambers are made of a special muscle called myocardium, which contract continuously and rhythmically to pump blood.

...okay, the heart...engine...the chambers...right and left atrium...right and left ventricle. Okay...special muscle...myocardium...mmmm...

Reads: The human heart has four chambers, the upper two chambers... the right side of the heart is responsible for pumping oxygen-poor blood to the lungs...This oxygen-poor blood feeds into two large veins, the superior vena cava and inferior vena cava. The right atrium conducts blood to the right ventricle, and the right ventricle pumps blood into the pulmonary artery. The pulmonary artery carries the blood to the lungs, where it picks up a fresh supply of oxygen and eliminates carbon dioxide.

This student exhibited a different learning process, with limited monitoring activities and use of a small subset of strategies. Such differences in how students learn explain variability in what they learn.

These two examples are consistent with the long held theoretical assumption that students actively construct knowledge in an idiosyncratic process (i.e., Constructivism; [3]). Ideally, students actively engage in the learning process, such as setting meaningful goals, selecting appropriate and task-specific strategies, monitoring motivational levels, and adapting based on feedback are all positively related to learning outcomes [1, 2, 4-12]. However, empirical research has provided process data that reveal the substantial individual differences with which students engage in the learning process. Certainly, individual cognitive characteristics (e.g., prior domain knowledge), motivational levels (e.g., selfefficacy), and developmental constraints affect how students learn. Aside from personal variables, the context can assume a particularly powerful role in how students approach the learning process and further develop their learning skills. Imagine, for example, a teacher who holds a personal belief that authority figures have knowledge that is inaccessible to novices. This teacher may resort to more didactic classroom practices, such as a reliance on lecturing/direct instruction, and thus may limit opportunities for students to engage and further develop learning skills. A fundamental question arises as to how teachers can best support students' development and use of learning processes. The goal of this paper is to examine research that has considered this broad question. The first step in examining this question is to articulate a theoretical framework that is robust enough to explain the complexities of learning. As such, the next section will first provide an overview of the Self-Regulated Learning (SRL) theory. Following this overview, SRL in the context of the classroom will be briefly examined and the role of the teacher in self-regulation will be introduced. Finally, a detailed rationale for this paper is provided at the conclusion of this section.

\section{Overview of SRL Theories}

In order to examine how teachers can best support their students' SRL, it is necessary to first understand how students can self-regulate their learning. Though the field of SRL has led to the development of distinct theoretical approaches that focus on a variety of constructs $[13,14]$, there are four common assumptions regarding how students can self-regulate their learning [15]. First, it is assumed that students can potentially monitor and regulate their cognition, behavior, and motivation, processes that are dependent on a number of factors including individual differences and developmental constraints. A second assumption suggests that students actively construct their own, idiosyncratic goals and meaning derived from both the learning context and their prior knowledge. Thus, students engage in a constructive process of learning. Not surprisingly, then, it is also assumed that all student behavior is goal-directed and the process of selfregulation includes modifying behavior to achieve goals. Lastly, it is assumed that self-regulatory behavior mediates the relationship between a student's performance, contextual factors, and individual characteristics. 
While these assumptions provide the foundation for most SRL theories (see [14] for an overview), specific approaches have been predominant in research examining how students self-regulate their learning within the context of the classroom. Zimmerman's [16] SRL theory is one of the most common theories in this line of research. In this model, self-regulation is composed of three phases: forethought, performance control, and self-reflection. In the first phase, the student "sets the stage" for the upcoming learning task. Self-regulated students develop realistic expectations, create goals with specific outcomes, and identify plans to maximize success in the particular learning task. It is in this phase that self-regulated students may ask themselves such questions as "Where is the best place for me to complete the work?", "What conditions will create challenges for me?", and "How will I start?" Performance control, the second phase of SRL in this theoretical approach, constitutes processes that are involved during learning. This phase includes specific strategies such as self-talk and self-monitoring that are used to maximize success on a learning task. Questions that self-regulated students may ask themselves in the second phase are "Am I following my plan correctly?", "Am I being distracted?", and "What strategies can I use to help me keep working?" Lastly, self-regulated students reflect at the conclusion of the learning activity, the third phase of SRL. This self-evaluation compares the performance outcome to goal(s). Self-regulated students in the phase will ask themselves such questions as "Did I meet all of the goals?", "Which conditions helped me be successful and what conditions distracted them?", and "Which strategies were effective given the context and learning activity?"

Pintrich [15] offers a slightly different perspective on how students can self-regulate their learning, with a comprehensive framework of four phases and four areas. The four phases include planning, monitoring, control, and reflection. These phases are intended to reflect common assumptions shared by many SRL models [17]. In phase one, the student plans, sets goals, and activates knowledge about the context, text, and self. Phase two is defined when the student exhibits metacognitive awareness and monitoring of cognition. In phase three, the student selects cognitive strategies and regulates different aspects of the context, task, and self. Lastly, in phase four, the student makes cognitive judgments and reflections on the context, task, and self. Within these individual phases, Pintrich [15] also proposes four different areas in which self-regulation can occur. Based on different psychological functioning (see [18]), the first three areas for regulation are cognition, motivation/affect, and behavior. The last area reflects contextual features, such as task characteristics, which can impede or facilitate an attempt to self-regulate their learning. As commonly suggested by most SRL theories, Pintrich's [15] model assumes that these phases are not hierarchical because they can occur concurrently and dynamically.

Winne and colleagues (i.e., [19-22]) offer another perspective that is guided by the Information Processing Theory (IPT). This model includes four phases of SRL: (1) understanding the task, (2) goal-setting and planning how to reach the goal(s), (3) enacting strategies, and (4) metacognitively adapting to studying. In the first phase, the student constructs a perception of the task from information in the learning context (Task Conditions) as well as information from prior experience and knowledge (Cognitive Conditions). The student develops goals and plans in the second phase, followed by selection and use of tactics and/or strategies in the third phase. Phase four includes monitoring activities and making cognitive evaluations about discrepancies between goal(s) and current domain knowledge. This model assumes that SRL has a recursive nature due to a feedback loop, during which discrepancies revealed by monitoring activities will lead self-regulated students to adapt their planning and/or strategies.

\section{SRL in the Classroom}

All three of these theoretical frameworks explicitly account for the role of context in students' SRL. The social cognitive approach to SRL (Zimmerman, 1994 [17]), for example, assumes that environmental factors have a bidirectional interaction with students' personal and behavioral characteristics. Interaction with the context results in cyclical development and adaptation of students' SRL. For example, teachers could foster their students' self-reflection by prompting them with questions such as "Did you meet all of the goals of the learning task?" and "Which strategies were effective for this particular learning task?" This prompting by the teacher may, in turn, foster the students' engagement in forethought as they "set the stage" for the subsequent, upcoming learning task.

Though the IPT approach $[20,21]$ offers distinct assumptions, it also provides an explanation of how context affects SRL. According to this theory, students develop perceptions of the learning task partly based on information provided in the context. This theory assumes a cyclical nature to SRL; information processed in one phase can become an input to subsequent information processing. Teachers' support of metacognitive monitoring, for example, can assist students in this critical component of SRL. These theoretical assumptions regarding the importance of the context and documented empirical relationships between SRL and learning outcomes have led to recommendations that classroom instruction should extend beyond factual knowledge. It has been argued that competencies with the process of learning, such as students' ability to selfregulate their learning, should be a central, explicit aim within education [23]. Thus, teachers' ability to support students' development of self-regulation should be carefully considered if students' SRL is an educational goal [24].

Research has also suggested that teachers should focus on their own self-regulated learning skills because it allows them to more deeply reflect on their own teaching practices, which can lead to increased student performance (Let and Lin 2003; Xiaodong et al., 2005). Others have argued that teachers need to be self-regulated learners themselves due to ever-changing curricular revisions, which require innovation and adaptability [25]. Teachers who engage in self-regulation are better able to meet these demands because 
they can balance a variety of professional demands, engage in reflective thinking, and embrace adaptation. Furthermore, a growing body of research has found a significant relationship between teachers' personal beliefs and their instructional pedagogy [26-28] (Shraw and Olafso, 2002). Teachers who are incapable of self-regulating their own learning and/or do not hold personal beliefs that students can engage in SRL are less likely to support the development of these capabilities in the classroom [29-31].

\section{Rationale of Literature Review}

Given the importance of SRL in the context of classrooms, it is not surprising that a rich body of empirical research has emerged examining how teachers support their students' self-regulation, as evidenced by literature reviews on classroom applications of SRL. For example, Paris and Paris [32] provide an incredibly informative literature review that categorizes relevant research into two groups, both of which focused on promoting SRL in students. One group of studies assumed a developmental view of SRL and sought to examine how students self-regulate learning to meet personal goals. A second group of studies examined the role of a transmission model in the acquisition of SRL. These studies considered the effect of explicit instruction in the use of self-regulated learning strategies. Such reviews have greatly advanced the field by providing clear and explicit guidelines for promoting SRL in the classroom. It was our aim to provide a literature review that offers a slightly different perspective from existing reviews by considering the methodological advancements recently used in this field of research (i.e., process data), discussing various theoretical frameworks guiding this research, and summarizing studies that empirically examined SRL with both pre-service and inservice teachers. This literature review aims to systematically consider each of these areas through the following research questions:

(1) What implications do the literature provide for supporting SRL in teacher education programs?

(2) What implications do the literature provide for supporting SRL with different kinds of teachers?

(3) How is SRL measured in research that examines selfregulation in the classroom?

\section{Method}

5.1. Criteria of Selection. The empirical studies selected for this Literature Review examined the teacher's role in relation to SRL. After the initial selection of articles, inclusion criteria were used to identify which studies would be examined for this Literature Review. These criteria centered on three main areas: (1) Theoretical Framework; (2) Focus on Teachers; and (3) Methodology.

First, studies were chosen that were explicitly guided by a SRL theory and used this theoretical framework as a lens to interpret the results. Studies were excluded from this review if they examined a specific process of SRL, such as strategy use, but did not explicitly reference a SRL theory. Secondly, studies had to include either pre-service or in-service teachers in the sample. Because our research questions consider the teacher's role in SRL, it was necessary for included studies to measure and assess teachers in some way. Third, the methodology of each study was evaluated in order to determine the soundness of its statistical analyses. In addition, the sample of the study needed to be appropriately described. Lastly, studies that focused on development of SRL measures were excluded due to the scope of this Literature Review.

5.2. Search Procedures. Based on a suggested framework for developing literature reviews (see [33]), the literature search was comprised of two stages: (1) Identify all relevant articles in an initial search; (2) Select articles to review based on inclusion criteria. First, a search for articles from the PsycInfo database was performed. During this initial literature search, a variety of keywords ("self-regulated learning"; "self-regulat*"; "SRL"; "teacher"; "student teacher"; "preservice teacher") from the articles' abstracts were used to identify the most relevant articles.

The first stage of the search produced 186 articles on SRL and teachers. In the second stage of the search, dissertation, chapters, literature reviews, and technical reports were removed from the pool of potential articles. In the third stage of the search, the inclusion criteria were applied to the remaining articles. The articles that were explicitly guided by a SRL theory, had a focus on in-service and/or pre-service teachers, and used a sound methodological approach were included. This final stage of the search, which concluded in June of 2011, resulted in 38 articles to be included in this Literature Review. Articles published after June of 2011 were not included in this Literature Review.

We examined these remaining articles for natural groupings and created three research questions that captured what we believe to be important components of the topic. The articles in these three main research questions were further divided into subsections illustrating specific trends within each question (see Figure 1 for the research questions and subsections). The organization of the articles for the first research question was not explicitly guided by predetermined categories, but rather was done post-hoc to determine the most natural groupings. This bottom-up approach was deemed to be most appropriate given there were no inherent assumed categories for this question, particularly when compared to the second and third research question. Many of the articles could have been placed in multiple categories so we assigned them according to the best fit (see Table 1 for complete list of articles, by research question). We chose thirteen of these articles to address the first research question, which considered the implications for teacher education programs. Nineteen studies examined the implications for in-service teachers supporting SRL with different kinds of teachers, our second research question. The final six articles formed a group relating to the third research question that considered how SRL is measured in the studies. 


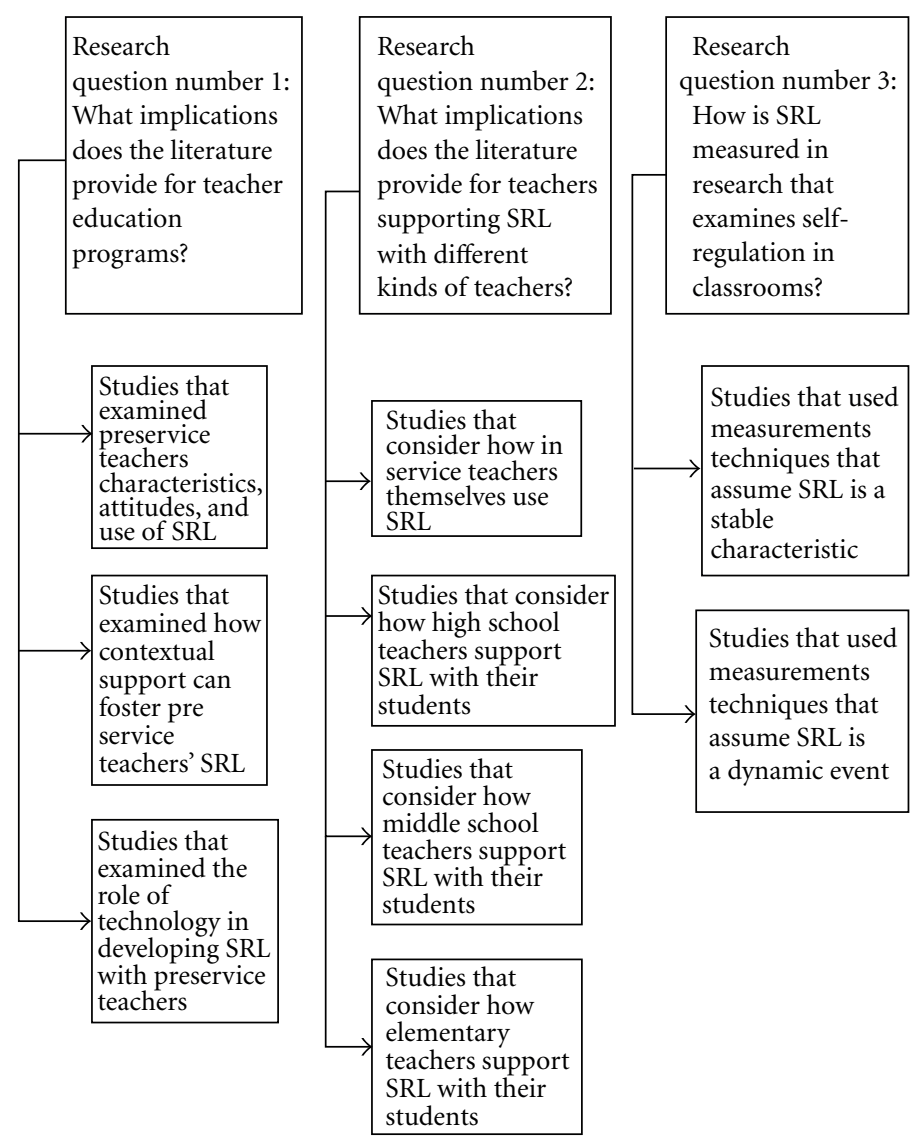

FIgURE 1: List of research questions and subsections.

\section{Results}

6.1. What Implications Does the Literature Provide for Teacher Education Programs? This section synthesizes studies that empirically examined self-regulation within populations of preservice teachers. Not surprisingly, a group of these reviewed studies considered the relationship between preservice teachers' characteristics and attitudes with SRL. For example, Bråten and Strømsø [34] examined the role of personal theories of intelligence and epistemological beliefs in "motivational and strategic components" of SRL with 108 student teachers and 178 business administration college students. Multiple regressions revealed a significant effect of personal beliefs on SRL. Specifically, beliefs about knowledge construction were a strong predictor of SRL for the student teachers. Other studies reveal that preservice teachers' personal beliefs regarding SRL may be conceptually different than their teacher educators. Kremer-Hayan and Tillema [35] interviewed 32 Israeli and 58 Dutch teacher educator, and student teachers in order to investigate potential differences in how these two groups view the meaning and implementation of SRL in the classroom. Somewhat surprisingly, the teacher educators were found to have a less positive attitude towards SRL and lower expectations about their competencies related to self-regulation. Other research has focused on the relationship between preservice teachers' motivation and use of learning strategies during education courses. Atputhasamy and Aun [36] found a positive relationship between those who used deeper level processing strategies such as metacognition and elaboration and learning goal orientation. Student teachers who reported an achievement goal orientation, on the other hand, used fewer self-regulatory processes, including organization and critical thinking.

The relationship between preservice teachers' personal beliefs and SRL raise the question of whether there is a developmental trajectory with their self-regulation competencies during teacher education programs. Some research has shown that appropriate contextual support can enhance SRL development. Hutchinson and Thauberger [37] present compelling evidence that student teachers can, in fact, be mentored to more effectively foster elementary children's use of SRL. Detailed analyses of transcripts revealed that a variety of scaffolding techniques during discussions support student teachers' development of SRL practices within elementary classrooms. Perry et al. [38] provide additional information on how student teachers can be mentored to design instructional contexts that support SRL. These two studies provide promising data that student teachers are capable of designing such tasks. These findings are contrary to the notion that several years of experience are required before teachers can begin to consider students' needs and 
TABLE 1: Complete list of reviewed studies by research question.

Research question 1: what implications does the literature provide for teacher education programs? $(n=13)$

Studies that examined preservice teachers' characteristics, attitudes, and use of SRL

(i) Bråten and Strømsø [34]

(ii) Kremer-Hayon and Tillema [35]

(iii) Atputhasamy and Aun [36]

Studies that examined how contextual support can foster preservice teachers' SRL

(i) Hutchinson and Thauberger [37]

(ii) Perry et al. [38]

(iii) Perry et al. [40]

(iv) Kramarski and Michalsky [29]

(v) Kramarski and Michalsky [41]

(vi) Michalsky and Kramarski [43]

(vii) Kramarski [44]

(viii) Kramarski and Revach [45]

Studies that examined the role of technology in developing SRL with preservice teachers

(i) Delfino et al. [25]

(ii) Dettori et al. [46]

Research question 2: what implications does the literature provide for teachers supporting SRL with different kinds of teachers? $(n=19)$

Studies that consider how inservice teachers themselves use SRL

(i) Kreber et al. [47]

(ii) Hoekstra et al. [51]

(iii) Tillema and Kremer-Hayon [48]

(iv) Van Eekelen et al. [49]

(vi) Gordon et al. [50]

Studies that consider how high school teachers support SRL with their students

(i) Oolbekkink-Marchand et al. [52]

(ii) Kistner et al. [53]

(iii) Veenman et al. [54]

(iv) Postholm [55]

Studies that consider how middle school teachers support SRL with their students

(i) Pauli et al. [56]

(ii) Cooper et al. [57]

Studies that consider how upper elementary teachers support SRL with their students

(i) Ee et al. [58]

(ii) Housand and Reis [59]

(iii) Meyer et al. [60]

(iv) Cartier et al. [61]

(v) Hilden [62]

Studies that consider how younger elementary teachers support SRL with their students

(i) Perry [63]

(ii) Perry and VandeKamp [64]

(iii) Perels et al. [65]

Research question 3: how is SRL measured in research that examines self-regulation in the classrooms? $(n=6)$

Studies that used measurements techniques that assume SRL is a stable characteristic

(i) Kramarski and Michalsky [29, 41, 66]

(ii) Lombaerts et al. [67]

(iii) Hwang and Vrongistinos [68]

Studies that used measurements techniques that assume SRL is a dynamic event

(i) Davis and Neitzel [69]

(ii) Perry et al [30]

(iii) van Eekelen et al. [49] 
abilities when planning and implementing instruction [39]. Direct scaffolding and explicit instruction, both in education courses and during student teaching, can assist preservice teachers' implementation of classroom tasks that offer autonomy, control challenge, and non threatening self and peer evaluations, all of which are hallmarks of classrooms that support SRL [38]. Perry et al. [40] also examined whether master teachers can mentor student teachers to develop and implement classroom practices that foster SRL in an elementary school setting. Data indicate mentoring is effective and that master teacher practices accounted for $20 \%$ of the variance observed in the student teachers' SRL practice.

Other research has turned to technology as a means to support preservice teachers' SRL development. Kramarski's robust and innovative line of research has evidenced the potential of emerging technology in preparing teachers, particularly for supporting self-regulation in the classroom. Kramarski and Michalsky [29], for example, investigated how the development of three dimensions (SRL in pedagogical context, pedagogical knowledge, and perceptions of teaching and learning) was affected by various contextual supports, namely, e-learning with and without SRL support and face-to-face learning with and without SRL support. In this study, preservice teachers randomly assigned to the e-learning condition were asked to solve pedagogical tasks (i.e., compare different types of cooperative learning) with a nonlinear technology environment. Preservice teachers assigned to the face-to-face condition, on the other hand, were asked to solve the same pedagogical tasks with material provided by the teacher (i.e., a more "traditional" classroom setting). Results indicated a significant effect of SRL support; those who received it in both the face-to-face and e-learning conditions outperformed those who did not receive it. However, those preservice teachers who received this support in the context of technology (e-learning) demonstrated highest SRL ability, pedagogical knowledge, and studentcentered learning perceptions. Kramarski and Michalsky [29] argue that the nature of emerging technology, such as the elearning environment used in this study, encourages the use of exploration, elaboration, and activation of prior knowledge because of its inherent nonlinear design. Therefore, explicit support of SRL in these environments promotes more active engagement of learning material. Kramarski and Michalsky [41] found similar results in another study that examined the effects of two hypermedia environments and SRL support with 95 preservice teachers. This study focused on a specific component of SRL, metacognition. Originally conceptualized as "thinking about thinking" (see Miller et al. 1970, p. 613), metacognition has more recently been conceptualized to include both the conscious awareness and regulation of one's own learning. Metacognition is a construct that focuses on processes related to the abstraction of existing or new cognitive structures [42]. A number of SRL theories highlight the importance of metacognition in self-regulation (e.g., [21]), noting its role in effective task execution. Metacognitive processes affect the use of cognitive activities, which support the acquisition and retention of knowledge ( $\mathrm{Ku}$ and $\mathrm{Ho}, 2010)$. Kramarski and Michalsky
[41] found that exposing preservice teachers to metacognitive support in hypermedia environments enhances their own metacognition. Participants who received metacognitive support during the experimental learning session demonstrated a significantly better ability to regulate and reflect on their own learning processes. Based on these findings, Kramarski and Michalsky [41] suggest that preservice teachers with more developed metacognition ability will be better prepared to support this aspect of SRL with their own students [43]. Other studies have shown that metacognitive scaffolding can effectively foster preservice teachers' ability to use SRL processes such as self-monitoring and evaluation strategies $[44,45]$.

Karmarski and colleagues' work has typically used technology as the context for SRL support. Given the emerging nature of technology in preservice teacher education, this context is important to consider. Online classrooms, distance education, and hybrid classroom settings are becoming more commonplace. Some argue that these environments can optimize the SRL development of preservice teachers. Delfino et al. [25], for example, used an interaction analysis to examine how collaborative activities in an online classroom can develop preservice teachers' ability to support students' SRL. Participants repeatedly demonstrated SRL, including self-reflection, self-awareness, and setting immediate goals. Dettori et al. [46] also examined the impact of online learning environment on preservice teachers' development of SRL. Their study identifies specific aspects of the environment that can foster self-regulation, including social competencies, motivational aspects and metacognitive and cognitive skills.

6.2. What Implications Do the Literature Provide for Supporting SRL with Different Kinds of Teachers Groups? A small subset of the reviewed studies for this research question focused on how inservice teachers themselves use SRL to learn new information and engage in professional development. Kreber et al. [47] used semistructured interviews to examine how 31 university science teachers engage in SRL when developing their expertise about teaching. Guided by both Zimmerman's SRL model [16] and Kreber and Cranton's Scholarship of Teaching model, the researchers came to the conclusion that individual differences in how university teachers engage in SRL are a product of educational development experiences. Workshops on teaching, active solicitation of student feedback, and adaptation of teaching practices positively affect SRL of university teachers. Tillema and Kremer-Hayon [48] found that in addition to previous experiences, personal beliefs of university teachers also affect the extent to which they engage in SRL. Data gathered from 12 Israeli and 17 Dutch teacher educators surprisingly suggest a divergence between teachers' pedagogy and the extent to which the teachers were engaging in SRL themselves. van Eekelen et al. [49] found similar results with fifteen experienced college teachers from The Netherlands. Using semi-structured interviews and a digital diary study, they found limited examples of teachers engaging in selfregulation with their learning. This somewhat surprising lack 
of SRL within this particular group of in-service teachers raises pedagogical issues and questions for teacher education programs, particularly if it is assumed that teachers' own selfregulatory behavior affects the classroom environment [50]. Research has suggested that changes in experienced teacher's self-regulatory behavior are related to their experimentation with new teaching methods and active reflection on the effectiveness of a variety of teaching methods [51].

From a developmental perspective, Oolbekkink et al. [52] considered the differences and similarities between 36 university and secondary teachers' perspectives on SRL. The researchers aimed to use teachers' perspective on SRL as an explanatory lens for why some students face a problematic transition from secondary to higher education. Not surprisingly, a qualitative analysis of the interview protocols in the study revealed that while university teachers focus on the variety of content, secondary teachers tend to consider the variety within students, particularly with how they engage in self-regulation. Kistner et al. [53] provide perspectives on how high school teachers support SRL with a study that included 20 German mathematics teachers and their 538 secondary students. A coding system was used to assess the teachers' explicit and implicit instruction of various SRL strategies, including motivation (resource management), metacognition (planning), and cognition (organization). Students' performance, which was measured before and after the learning lesson, was positively related to cognitive strategies. However, these researchers also note that while explicit instruction of cognitive strategies was positively related to student performance (more so than implicit instruction), the occurrence of this embedded instruction was rare. Veenman et al. [54] provide a potential explanation for the rarity of explicit SRL instruction in high school classrooms. This study included a SRL training program for 25 Dutch secondary school teachers, with a quasiexperimental, treatment-control group. Classroom observations and ratings from both teachers and students led to the conclusion that the SRL training program had little effect on classroom practices. It was concluded that training secondary teachers to explicitly embed the instruction of SRL strategies is time consuming and effects may not been seen immediately. Actively embedding SRL instruction is important, though, even for the older development group of high school students. Research has demonstrated that students of this age benefit from explicit instruction and teachers' willingness to adapt classroom practices to meet their developmental level with respect to SRL [55].

Substantially fewer studies have considered the role of the middle school teacher in supporting SRL. Pauli et al. [56] explored the extent to which 8th grade math teachers implement various features of SRL to promote problem solving and mathematical modeling. Measurement techniques included videotapes of lessons, student and teacher questionnaires, and math achievement tests. Teachers reported how frequently they provided opportunities for SRL and independent problem solving. Results indicate that teachers' personal beliefs influenced the extent to which they fostered independent problem solving. Furthermore, opportunities for SRL were positively related to students' learning experience. However, research has demonstrated that these opportunities need to be explicit to the students, as evidenced by Cooper et al. [57] study. This study examined how 7 th grade high school English teachers can foster SRL. The researchers collaborated with the participating teachers, meeting once a week over a three-month period to discuss how to design higher-order reasoning questions in a myriad of class assignments. Interviews revealed that conscious and explicit embedded instruction of SRL resulted in students' increased understanding of self-regulation, particularly with goal setting.

Research has supported the assumption that SRL can be fostered with even younger students in upper elementary grades. Ee et al. [58] study examined the relationship between teachers' goal orientations and instructional practices with their Primary 6 students' SRL. The sample included 566 high achieving Primary 6 students and 32 teachers across 34 Singapore schools. Surprisingly, this study found a negative relationship between teachers' explicit SRL instruction (primarily cognitive strategies) and students' ego goal orientation. One explanation is that participants were all high-achieving and thus may have reached a certain level of automaticity with the use of cognitive strategies. As a consequence, explicit instruction of a skill that was already possessed may have had negative motivational effects on the students. This somewhat surprising finding concerning explicit SRL instruction with middle school students contradicts other findings with upper elementary students. For example, Hilden and Pressley [62] found evidence that a year-long professional development program in which 5th grade teachers were trained how to explicitly teach SRL resulted in the improvement of both their reading comprehension instruction and their students' self-regulated use of comprehensive strategies.

These two findings suggest that the effectiveness of explicit SRL instruction may be mediated by personal characteristics. Housand and Reis [59] present an argument that gifted and high achieving students as early as fifth grade may have already obtained the capacity to engage in a variety of SRL processes. Their findings suggest some upper elementary students demonstrate the ability to engage in self-regulation even in classrooms that are characterized as low self-regulation. Though fewer in numbers, these studies indicate that while the environment certainly can affect the development of SRL, there are personal characteristics that play a role. However, it is commonly assumed that in addition to personal characteristics the context of the environment and instructional opportunities need to be clearly considered, if SRL is an educational goal [61]. Some research has pointed to technology as an instructional opportunity to foster self-regulation for upper elementary students. Meyer et al. [60], for example, examined the impact of an electronic portfolio, ePEARL, on the literacy and SRL of 296 4th-6th graders across three Canadian provinces. The 14 teachers who participated in this study reported that the use of this electronic portfolio had a positive impact on their SRL teaching strategies and that the students' increased literacy was a result of the planning and reflecting required by this learning tool. 
Given the developmental trajectory of students' SRL, it has been questioned whether younger elementary students can engage in SRL. Perry and colleagues have added significant work in this area. Their rich line of research has provided compelling evidence that the youngest elementaryaged students are capable of self-regulating their learning. Perry's earlier work [63] challenged the notion that young children lack the capacity to engage in SRL and adapt their motivational orientations. Contextual factors of the environment can provide the necessary support for students as young as 2nd and 3rd grade to develop the ability to self-regulate their learning. Classroom observations led Perry and VandeKamp [64] to the conclusion that nonthreatening evaluation practices, involvement in complex reading and writing activities, the provision of autonomy related to what the students read and write about, and the ability to modify learning tasks to control challenge are all contextual features of classrooms that promote SRL in younger elementary-aged children. Others have shared Perry's findings, such as Perels et al. [65]. This study examined the effect of SRL training on 35 German kindergarten teachers. Results from teacher selfreport questionnaires and student interviews suggest that training effectively improves teachers' ability to foster SRL with students as young as preschool.

In sum, these lines of research suggest that teachers of different age groups distinctly support SRL in their classrooms. Generally speaking, research has found limited examples of learning opportunities that support SRL in university and college classrooms [49]. Findings suggest that these teachers tend to focus on the content of their class. On the other hand, secondary (high school) teachers tend to consider the variety within students, particularly with how they engage in self-regulation [52]. However, research suggests that while high school teachers may offer more opportunities for students to engage in SRL, these experiences may be implicit in the teacher's pedagogical approach [53]. Explicit instruction of SRL is not readily apparent in high school teachers' instruction, findings that have also been replicated within middle school classrooms. Though middle school students benefit from explicit SRL instruction, teachers of this developmental group do not routinely integrate this component into lesson plans [57]. Quite surprisingly, while empirical documentation of explicit teacher support with middle and high school students' SRL has not been substantially documented, research at the elementary level suggests that these teachers do, and should, support SRL. Nonthreatening evaluation practices, involvement in complex reading and writing activities, the provision of autonomy related to what the students read and write about, and the ability to modify learning tasks to control challenge are all pedagogical practices observed of elementary school teachers that promote SRL [64].

One common thread among the empirical findings from different groups of teachers is the existence of individual differences in how they support SRL. While the findings suggest some differences between groups of teachers, there are also distinctions within these groups of teachers. The findings suggest that personal beliefs explain these individual differences, an assumption that is supported by previous work. Sugrue [70] argued that teacher's beliefs are the latent foundation for their behaviors and instructional decisions, a notion that has been supported by various lines of research (see [71-75]). For example, teachers who hold personal beliefs that authority figures have knowledge that is otherwise inaccessible may resort to classroom practices that do not explicitly support SRL, such as lecture/direct instruction. Furthermore, previous research suggests that teachers' beliefs concerning student capacities affect implementation and planning of instruction [76]. For example, teachers are more likely to integrate student-centered activities in their instruction planning if they believe their students have the capacity to be active participants in their own learning. Taken together, future research would be well served to consider the interaction between the personal beliefs of inservice and preservice teachers and their instructional support of SRL.

6.3. How Is Self-Regulation Measured in Research That Examines How SRL Is Supported in the Classroom? The empirical research reviewed for the first two research questions illustrates how teachers support SRL in the classroom. Clearly self-regulation affects learning, and thus the teachers' role in supporting SRL is an important topic to empirically explore. Critical examinations of the teacher's role, though, are incomplete without consideration of the methodology behind the research. Researchers have used a variety of measures to examine SRL in the classroom, each of which reflects a distinct perspective of the underlying properties of self-regulation. Thus, a review of how teachers support SRL needs to also examine the underlying methodology. Winne (1997) and Winne and Perry [22] proposed that SRL could be viewed as having one of two properties, aptitude or event. An aptitude is a relatively enduring trait of an individual, which can be used to predict future behavior [13]. Based on this assumption, self-perceptions are considered valid measures of SRL. These perceptions often are derived from self-report questionnaires [22]. Relatively easy to administer and score, self-report questionnaires are an efficient tool in measuring students' self-perception of how they regulate their learning. On the other hand, viewing self-regulation as an event suggests that SRL unfolds within particular contexts and self-regulatory processes are dynamic unfolding events [13]. Several different protocols have been used to measure SRL as an event, including error detection tasks, observations, concurrent and retrospective think-alouds, and diaries.

A majority of the reviewed studies assumed SRL is a stable characteristic (i.e., an aptitude), as evidenced by their use of self-report questionnaires. The Motivated Strategies for Learning Questionnaire (MSLQ) has received considerable attention within this body of research. This selfreport questionnaire includes declarations and conditional relations and was developed to assess "college students' motivational orientations and their use of different learning strategies for a college course" ([77]; page 3). Kramarski and Michalsky [66] used the MSLQ to investigate the effect of metacognitive prompts in a web-based learning environment for 144 first-year preservice teachers. Results from this self-report questionnaire found that supporting the participants' through the evaluation phase [16] was the 
most effective approach for fostering their perceived SRL in both learning and teaching contexts. Research has also used the MSLQ to examine the effect of diaries on preservice teachers development of SRL. Arsal [78] presented data that suggests preservice teachers' metacognition and time management can be improved by asking them to self-report their engagement in SRL use with a daily diary. Others have used revised versions of the MSLQ, such as Hwang and Vrongistinos [68]. The College Students' Self-Regulated Learning Questionnaire (CSSRQ) is a revised version of the MSLQ and consists of 93 items related to seeking help, time management, regulatory process, metacognition, critical thinking, organization, elaboration, rehearsal, selfefficacy, causal attributions, task value, extrinsic motivation, and intrinsic motivation. All items are answered on a Likert scale ranging from 1 (not at all true) to 6 (very true). This study found that the academic performance of inservice teachers is positively related to self-reported use of SRL processes. High-achieving inservice teachers were more likely to engage in elaboration, metacognition, and other self-regulatory processes. Lombaerts et al. [67] used a different self-report questionnaire, the Self-Regulated Learning Inventory for Teachers (SRLIT) to assess elementary teachers' perceptions of SRL practices (Lombaerts, Engels, and Athanasou, 2007). The SRLIT consists of three subscales that represent Zimmerman's SRL model [16]: forethought, performance control, and self-reflection. The questionnaire contains 23 items answered on a six-point Likert scale ranging from 0 (never) to 5 (always). Results indicated that while demographic and background variables did not affect teachers' SRL recognitions, teacher-level variables had a positive impact. Beliefs concerning the influence of SRL in elementary school settings and school context satisfaction both positively are related to the teachers' self-reported SRL recognition.

Other lines of research have taken a different methodological approach by assuming SRL is a dynamic event that should be captured in real time. For example, Perry et al. [30] used observations of mentor and student teachers, videotapes of professional seminars, and samples of student teachers' reflections on lesson plans to capture how beginning teachers support SRL. Perry and colleagues [30, 79] have argued that process data, such as observations and other running records, address many of the challenges of measuring SRL in a valid manner. Observations and running records allow for the measurement of self-regulation in real time and enable the researcher to accurately identify behavior and classroom contexts that effectively support SRL. These measurements do not rely on the teacher or students' ability to predict how they will support SRL or use self-regulatory processes in the classroom, making these measurements ostensibly more accurate. Davis and Neitzel [69] have also used observational data to examine upperelementary and middle school teachers' conceptions of their classroom practices. This methodological approach revealed that the teachers generally did not create an environment that optimally supported the development of their students' SRL, despite the teachers' deep understanding of classroom assessment.

\section{Discussion}

7.1. Overview. Theoretical assumptions that individual differences exist in student learning have been supported by empirical research. Paper, such as the one provided by Paris and Paris [32], offer a synthesis of this research and provide critical implications for how teachers can support their students' learning. Our goal in writing this paper was to extend the current research by summarizing studies that empirically examined SRL with preservice and/or inservice teachers. The following research questions guided the scope of this paper: (1) What implications do the literature provide for supporting SRL in teacher education programs? (2) What implications do the literature provide for supporting SRL with different kinds of teachers? (3) How is SRL measured in research that examines self-regulation in the classroom? The studies that were reviewed for these three questions provide theoretical, methodological, and practical implications for research that focuses on how teachers can support SRL.

7.2. Theoretical Implications. While a variety of SRL theories have guided research in this area, Zimmerman's [16] theory has been the most frequently cited in the reviewed studies. For example, Perels et al. [65] used this theory to guide their research on the effect of training 35 German kindergarten teachers on developing their own self-regulation skills and SRL within their students. Results are similar to that of Perry's research. Findings suggest that students as young as kindergarten have the capacity to self-regulate and training can effectively support teachers' ability to create classroom environments that foster SRL. Others have used Zimmerman's theory to examine the SRL of experienced teachers, including Hoekstra et al.'s [51]. This study examined changes in SRL of 32 teachers in informal learning environments. The findings suggest individual differences regarding how teachers change their SRL orientation. The extent to which teachers reflected on the effectiveness of their lessons seemed to positively correlate with conceptions of SRL. Zimmerman's [16] perspective of SRL has understandably been the predominant theory in this line of research. It offers a robust, explanatory lens that articulates the bidirectional interaction with students' personal and behavioral characteristics and their environment, as evidenced by both Perels et al. [65] and Hoekstra's [51] studies.

Other SRL theories have received less empirical attention in this line of research but are worth considering. Winne's model (i.e., [21, 22]), for example, provides unique assumptions that should be more closely examined with research considering the broad question of how teachers can support their students' SRL. This particular model of SRL stresses the role of metacognitive monitoring in the process of self-regulation. When students engage in metacognitive monitoring, they identify potential discrepancies between any teacher and/or student set goals and their current profile on a task $[19,20]$. As such, metacognitive monitoring provides internally generated feedback, which assists students in adapting their SRL. Furthermore, metacognition allows students to regulate and govern task execution and is a critical process in the acquisition and retention of knowledge 
(Ku and Ho, 2010). As Michalsky and Kramarski [43] have argued, teachers with more developed metacognitive ability themselves will be better equipped to support this critical aspect of SRL. While Kramarski's body of research has provided robust findings on types of metacognitive scaffolds that can foster preservice teachers' ability to use processes such as self-monitoring, there remains a paucity of research that is guided by Winne's model of SRL (i.e., [21, 22]).

7.3. Methodological Implications. In addition to theoretical considerations, the reviewed studies also provide methodological implications. A vast majority utilized self-report questionnaires to measure SRL, most notably the MSLQ [77]. This methodological approach assumes that selfregulatory processes are stable. Furthermore, self-report measures assume that both students and teachers can accurately report how they engage in the learning and teaching process. However, Perry et al. [79] suggest that self-regulatory processes should be examined in real time because SRL is an ongoing process that unfolds within particular contexts. As such, recent research has advocated that SRL should be considered an event and that selfregulation data should be collected during learning $[22,63$, 80-82]. A smaller body of the reviewed studies utilized this type of process data. For example, Perry and colleagues' have successfully employed observations to measure both teachers and students' SRL, even with students as young as 2nd grade [63]. Other forms of process data may provide additional measures to successfully capture SRL in the classrooms.

The think-aloud, which has recently emerged as a useful protocol to measure SRL with emerging technologies (e.g., $[4,8,11,12,83,84])$, offers an additional approach to capturing SRL in the classroom. This protocol is an online trace methodology that captures SRL during learning [80]. The think aloud has an extensive history in cognitive psychology and cognitive science (see [85-87]), where both concurrent and retrospective think-aloud protocols are used as data sources for cognitive processes [88]. While the think-aloud protocol has been most popular in reading comprehension $[89,90]$, it has been shown as an excellent tool to gather verbal accounts of SRL and to map out self-regulatory processes during learning (e.g., $[13,84]$ ). Concurrent think-aloud protocols may be most appropriate with empirical research examining how preservice teachers use SRL. A concurrent think-aloud protocol asks participants to verbalize their thoughts, but not describe or explain what they are doing, while performing a task [86]. Based on the assumption that thought processes are a sequence of states and that information in a state is relatively stable [85] (Ericsson and Simon, 1993), verbalizing thoughts during learning will not disrupt the learning process. Empirical evidence has supported this assumption and suggested that an appropriately designed experimental session with a concurrent think-aloud protocol will not significantly affect cognitive and metacognitive processes during learning (i.e., [91-93]). An alternative approach is a retrospective thinkaloud protocol, which involves participants verbalizing their thoughts following the completion of the task. For example, a teacher's lesson would be video and audio recorded without any disruption from the researcher(s) (other than the recording). Following the completion of the lesson, the teacher would watch the video and verbalize thoughts as they relate to how he or she supported SRL in the classroom. The teacher's firsthand account of how she or he supports SRL in the classroom diminishes potential validity issues associated with self-report questionnaires.

7.4. Practical Implications. Students' ability to actively engage with the learning material, such as setting appropriate goals, accurately monitoring their emerging understanding, and adapting the use of strategies, are critical competencies that should be a central, explicit aim within education [23]. Despite the importance of these self-regulatory processes, several of the reviewed studies suggest that explicit instruction of SRL is often rare. Veenman et al. [54], for example, found that the occurrence of embedded instruction of cognitive strategies was rare in high school classrooms. Why might teachers rarely integrate explicit SRL instruction into their lesson plans when it is shown to be effective? The reviewed studies indicate that this answer is not related to the effectiveness of training, professional development, and/or scaffolding. Empirical research has demonstrated that professional development programs are effective in improving teachers' ability to explicitly teach SRL within their classroom (e.g., [62]). Furthermore, Perry and colleagues provide robust evidence that student teachers can improve their ability to create classroom tasks that offer autonomy, and nonthreatening self and peer evaluations, as well as control challenge with the assistance of direct scaffolding from expert teachers. If, then, professional development and scaffolding can support inservice and preservice teachers' ability to create classrooms that support SRL, what accounts for an apparent rarity in this type of instruction $[49,54]$ ?

Research suggests that changes in experienced teacher's support of SRL in the classroom are related to their willingness to experiment with new teaching methods and active reflection on the effectiveness of various teaching methods [51]. Furthermore, empirical findings indicate that instructional practices are significantly associated with personal beliefs (e.g., [74]). Sugrue [70], for example, found that teachers' beliefs are the latent foundation for their behaviors and instructional decisions, a notion that has been supported by various lines of research (see $[71,72,75]$ ). Bruning et al. [76] further suggests that teachers' behavior is directly aligned with their beliefs concerning specific components of the classroom, including beliefs about course content and teaching. Teachers' treatment of course content is, in part, dependent on their views about the nature of knowledge. Collectively, these beliefs represent personal epistemology, a field of study that has enjoyed a long history (Perry, 1970). Originally describing the understanding of knowledge as a progression from dualistic to relativist thinking, the field of epistemology has evolved and models have emerged suggesting that epistemology is composed of distinct dimensions (e.g., [27, 94-99]). Teachers' beliefs 
regarding teaching, on the other hand, relate to the implementation and planning of instruction [76], which is affected by a teacher's personal epistemology. Take, for example, a hypothetical teacher who has a more naïve personal epistemology and thus believes that knowledge is certain and absolute. This particular teacher would be more likely to resort to didactic instruction, which is not a characteristic of classrooms that support SRL. While this hypothetical teacher may have the capacity to learn how to support SRL in the classroom through a training program, personal beliefs mediate the teacher's willingness to do so. Thus, it would stand to reason that any SRL professional development for inservice teachers and direct SRL instruction to preservice teachers should be accompanied by consideration of their personal epistemologies. The formulation of personal beliefs in teacher education programs can create the foundation that guides teachers' behavior in the classroom.

In addition to considering personal beliefs of teachers, successful implementation of learning tasks that support SRL requires careful consideration of students' needs and abilities. A number of the reviewed studies support the notion that explicit SRL instruction has positive effects in the classroom. Kistner et al. [53] found that high school math teachers' explicit instruction of SRL was positively related to their students' performance, findings that were echoed in middle school students (e.g., [57]) as well as elementary students (e.g., [62, 63]). However, the reviewed studies also provide empirical evidence that explicit SRL instruction may not always benefit students. Ee et al. (2010) found a negative relationship with this type of instructional practice and the motivation of high-achieving students. The researchers suggest that the students in this study were all high achieving and had reached automaticity with cognitive strategies. Thus, the execution and retrieval of cognitive strategies for these students did not require the use of any of the working memory resources [100]. Automaticity bypasses the limited space associated with working memory and allows cognitive resources to be used in other capacities. In other words, students who already have the capacity to use cognitive strategies may have adverse reactions to explicit instruction with these SRL processes. As with any other classroom practice, optimal SRL instruction requires the consideration of students' individual differences with their self-regulation ability.

\section{References}

[1] D. C. Moos and R. Azevedo, "Self-regulated learning with hypermedia: the role of prior domain knowledge," Contemporary Educational Psychology, vol. 33, no. 2, pp. 270-298, 2008.

[2] D. C. Moos and R. Azevedo, "Exploring the fluctuation of motivation and use of self-regulatory processes during learning with hypermedia," Instructional Science, vol. 36, no. 3, pp. 203-231, 2008.

[3] J. Piaget, Intelligence and Affectivity: Their Relationship During Child Development, Annual Review, Inc., Palo Alto, Calif, USA, 1954.
[4] R. Azevedo, "Understanding the complex nature of selfregulatory processes in learning with computer-based learning environments: an introduction," Metacognition and Learning, vol. 2, no. 2-3, pp. 57-65, 2007.

[5] R. Azevedo, "The role of self-regulation in learning about science with hypermedia," in Recent Innovations in Educational Technology That Facilitate Student Learning, D. Robinson and G. Schraw, Eds., pp. 127-156, Information Age Publishing, Charlotte, NC, USA, 2008.

[6] R. Azevedo, J. A. Greene, and D. C. Moos, "The effect of a human agent's external regulation upon college students' hypermedia learning," Metacognition and Learning, vol. 2, no. 2-3, pp. 67-87, 2007.

[7] R. Azevedo, A. Johnson, A. Chauncey, and C. Burkett, "Selfregulated learning with MetaTutor: advancing the science of learning with MetaCognitive tools," in New Science of Learning: Computers, Cognition, and Collaboration in Education, M. Khine and I. Saleh, Eds., pp. 225-247, Springer, Amsterdam, The Netherlands, 2010.

[8] J. A. Greene and R. Azevedo, "A macro-level analysis of SRL processes and their relations to the acquisition of a sophisticated mental model of a complex system," Contemporary Educational Psychology, vol. 34, no. 1, pp. 18-29, 2009.

[9] D. C. Moos, "Note-taking while learning hypermedia: cognitive and motivational considerations," Computers in Human Behavior, vol. 25, no. 5, pp. 1120-1128, 2009.

[10] D. C. Moos, "Nonlinear technology: changing the conception of extrinsic motivation?" Computers and Education, vol. 55, no. 4, pp. 1640-1650, 2010.

[11] D. C. Moos, "Self-regulated learning with hypermedia: too much of a good thing?" Journal of Educational Multimedia and Hypermedia, vol. 19, no. 1, pp. 59-77, 2010.

[12] D. C. Moos, "Self-regulated learning and externally generated feedback with hypermedia," Journal of Educational Computing Research, vol. 44, no. 3, pp. 265-297, 2011.

[13] M. Boekaerts, P. Pintrich, and M. Zeidner, Eds., Handbook of Self-Regulation, Academic Press, San Diego, Calif, USA, 2000.

[14] B. J. Zimmerman and D. H. Schunk, Eds., Self-Regulated Learning and Academic Achievement: Theoretical Perspectives, Erlbaum, Mahwah, NJ, USA, 2nd edition, 2001.

[15] P. Pintrich, "The role of goal orientation in self-regulated learning," in Handbook of Self-Regulation, M. Boekaerts, P. Pintrich, and M. Zeidner, Eds., pp. 452-502, Academic Press, San Diego, Calif, USA, 2000.

[16] B. J. Zimmerman, "Attaining self-regulation: a social cognitive perspective," in Handbook of Self-Regulation, pp. 13-39, Academic Press, San Diego, Calif, USA, 2000.

[17] B. J. Zimmerman, "Theories of self-regulated learning and academic achievement: an overview and analysis," in SelfRegulated Learning and Academic Achievement: Theoretical Perspectives, B. J. Zimmerman and D. Schunk, Eds., pp. 1-37, Erlbaum, Mahwah, NJ, USA, 2001.

[18] R. Snow, L. Corno, and D. Jackson, "Individual differences in affective and cognitive functions," in Handbook of Educational Psychology, D. Berliner and R. Calfee, Eds., pp. 243310, Macmillan, New York, NY, USA, 1996.

[19] D. L. Butler and P. H. Winne, "Feedback and self-regulated learning: a theoretical synthesis," Review of Educational Research, vol. 65, no. 3, pp. 245-281, 1995.

[20] P. H. Winne, "Self-regulated learning viewed from models of information processing," in Self-Regulated Learning and Academic Achievement: Theoretical Perspectives, B. Zimmerman and D. Schunk, Eds., pp. 153-189, Erlbaum, Mahwah, NJ, USA, 2001 
[21] P. H. Winne and A. F. Hadwin, "Studying self-regulated learning," in Metacognition in Educational Theory and Practice, D. J. Hacker, J. Dunlosky, and A. Graesser, Eds., pp. 277 304, Erlbaum, Hillsdale, NJ, USA, 1998.

[22] P. H. Winne and N. E. Perry, "Measuring self-regulated learning," in Handbook of Self-Regulation, M. Boekaerts, P. Pintrich, and M. Zeidner, Eds., pp. 531-566, Academic Press, Orlando, Fla, USA, 2000.

[23] OECD, PISA Learning for Tomorrow's World: First Results from PISA 2003, OECD Publishing, 2004.

[24] C. A. Wolters and P. R. Pintrich, "Contextual differences in student motivation and self-regulated learning in mathematics, English, and social studies classrooms," Instructional Science, vol. 26, no. 1-2, pp. 27-47, 1998.

[25] M. Delfino, G. Dettori, and D. Persico, "An online course fostering self-regulation of trainee teachers," Psicothema, vol. 22, no. 2, pp. 299-305, 2010.

[26] B. K. Hofer and P. R. Pintrich, Personal Epistemology: The Psychology of Beliefs about Knowledge and Knowing, Lawrence Erlbaum, Mahwah, NJ, USA, 2002.

[27] K. R. Muis and M. J. Foy, “The effects of teachers' beliefs on elementary students' beliefs, motivation, and achievement in mathematics," in Personal Epistemology in the Classroom: Theory, Research, and Implications for Practice, L. D. Bendixen and F. C. Feucht, Eds., pp. 516-551, Cambridge University Press, New York, NY, USA, 2010.

[28] F. Pajares, "Teachers' beliefs and educational research: cleaning up a messy construct," Review of Educational Research, vol. 62, no. 3, pp. 307-332, 1992.

[29] B. Kramarski and T. Michalsky, "Investigating preservice teachers' professional growth in self-regulated learning environments," Journal of Educational Psychology, vol. 101, no. 1, pp. 161-175, 2009.

[30] N. E. Perry, L. Phillips, and L. Hutchinson, "Mentoring student teachers to support self-regulated learning," Elementary School Journal, vol. 106, no. 3, pp. 237-254, 2006.

[31] J. Randi and L. Corno, "Teacher innovations in the selfregulated learning," in Handbook of Self-Regulation, M. Boekarts, P. R. Pintrich, and M. Zeidner, Eds., pp. 651-685, Academic Press, San Diego, Calif, USA, 2000.

[32] S. G. Paris and A. H. Paris, "Classroom applications of research on self-regulated learning," Educational Psychologist, vol. 36, no. 2, pp. 89-101, 2001.

[33] C. Hart, Doing a Literature Review: Releasing the Social science Research Imagination, Sage, London, UK, 1999.

[34] I. Bråten and H. I. Strømsø, "The relationship between epistemological beliefs, implicit theories of intelligence, and self-regulated learning among Norwegian postsecondary students," British Journal of Educational Psychology, vol. 75, no. 4, pp. 539-565, 2005.

[35] L. Kremer-Hayon and H. H. Tillema, "Self-regulated learning in the context of teacher education," Teaching and Teacher Education, vol. 15, no. 5, pp. 507-522, 1999.

[36] L. Atputhasamy and T. K. Aun, "Association between motivation and self-reported use of learning strategies by trainee teachers," Korean Journal of Thinking \& Problem Solving, vol. 16, no. 1, pp. 39-51, 2006.

[37] N. E. Perry, L. Hutchinson, and C. Thauberger, "Talking about teaching self-regulated learning: scaffolding student teachers' development and use of practices that promote self-regulated learning," International Journal of Educational Research, vol. 47, no. 2, pp. 97-108, 2008.

[38] N. E. Perry, L. Hutchinson, and C. Thauberger, "Mentoring student teachers to design and implement literacy tasks that support self-regulated reading and writing," Reading and Writing Quarterly, vol. 23, no. 1, pp. 27-50, 2007.

[39] F. F. Fuller and O. H. Bown, "Becoming a teacher," in Teacher Education: The 74th Yearbook of the National Society for the Study of Education, Part II, K. Ryan, Ed., pp. 25-52, University of Chicago Press, Chicago, Ill, USA, 1975.

[40] N. Perry, L. Phillips, and J. Dowler, "Examining features of tasks and their potential to promote self-regulated learning," Teachers College Record, vol. 106, no. 9, pp. 1854-1878, 2004.

[41] B. Kramarski and T. Michalsky, "Preparing preservice teachers for self-regulated learning in the context of technological pedagogical content knowledge," Learning and Instruction, vol. 20, no. 5, pp. 434-447, 2010.

[42] D. L. Dinsmore, P. A. Alexander, and S. M. Loughlin, "Focusing the conceptual lens on metacognition, self-regulation, and self-regulated learning," Educational Psychology Review, vol. 20, no. 4, pp. 391-409, 2008.

[43] T. Michalsky and B. Kramarski, "Developing self-regulated learning of pre-service teachers in computer mediated communication in relation to conceptions about teaching and learning," Megamot, vol. 45, no. 4, pp. 765-798, 2008.

[44] B. Kramarski, "Promoting teachers' algebraic reasoning and self-regulation with metacognitive guidance," Metacognition and Learning, vol. 3, no. 2, pp. 83-99, 2008.

[45] B. Kramarski and T. Revach, "The challenge of self-regulated learning in mathematics teachers' professional training," Educational Studies in Mathematics, vol. 72, no. 3, pp. 379399, 2009.

[46] G. Dettori, T. Giannetti, and D. Persico, "SRL in online cooperative learning: implications for pre-service teacher training," European Journal of Education, vol. 41, no. 3-4, pp. 397-414, 2006.

[47] C. Kreber, H. Castleden, N. Erfani, and T. Wright, "Selfregulated learning about university teaching: an exploratory study," Teaching in Higher Education, vol. 10, no. 1, pp. 75-97, 2005.

[48] H. H. Tillema and L. Kremer-Hayon, "'Practicing what we preach'-teacher educators' dilemmas in promoting selfregulated learning: a cross case comparison," Teaching and Teacher Education, vol. 18, no. 5, pp. 593-607, 2002.

[49] I. M. van Eekelen, H. P. A. Boshuizen, and J. D. Vermunt, "Self-regulation in higher education teacher learning," Higher Education, vol. 50, no. 3, pp. 447-471, 2005.

[50] S. C. Gordon, M. H. Dembo, and D. Hocevar, "Do teachers' own learning behaviors influence their classroom goal orientation and control ideology?" Teaching and Teacher Education, vol. 23, no. 1, pp. 36-46, 2007.

[51] A. Hoekstra, M. Brekelmans, D. Beijaard, and F. Korthagen, "Experienced teachers' informal learning: learning activities and changes in behavior and cognition," Teaching and Teacher Education, vol. 25, no. 5, pp. 663-673, 2009.

[52] H. W. Oolbekkink-Marchand, J. H. van Driel, and N. Verloop, "A breed apart? A comparison of secondary and university teachers' perspectives on self-regulated learning," Teachers and Teaching: Theory and Practice, vol. 12, no. 5, pp. 593-614, 2006.

[53] S. Kistner, K. Rakoczy, B. Otto, C. Dignath-van Ewijk, G. Büttner, and E. Klieme, "Promotion of self-regulated learning in classrooms: investigating frequency, quality, and consequences for student performance," Metacognition and Learning, vol. 5, no. 2, pp. 157-171, 2010.

[54] S. Veenman, D. Beems, S. Gerrits, and G. Op de Weegh, "Implementation effects of a training program for self-regulated 
learning," Journal of Research \& Development in Education, vol. 32, no. 3, pp. 148-159, 1999.

[55] M. B. Postholm, "Self-regulated pupils in teaching: teachers' experiences," Teachers and Teaching: Theory and Practice, vol. 16, no. 4, pp. 491-505, 2010.

[56] C. Pauli, K. Reusser, and U. Grob, "Teaching for understanding and/or self-regulated learning? A video-based analysis of reform-oriented mathematics instruction in Switzerland," International Journal of Educational Research, vol. 46, no. 5, pp. 294-305, 2007.

[57] J. E. Cooper, S. Horn, and D. B. Strahan, "If only they would do their homework: promoting self-regulation in high school english classes," The High School Journal, vol. 88, no. 3, pp. 10-25, 2005.

[58] J. Ee, P. J. Moore, and L. Atputhasamy, "High-achieving students: their motivational goals, self-regulation and achievement and relationships to their teachers' goals and strategybased instruction," High Ability Studies, vol. 14, no. 1, pp. 23 39, 2003.

[59] A. Housand and S. M. Reis, "Self-regulated learning in reading: gifted pedagogy and instructional settings," Journal of Advanced Academics, vol. 20, no. 1, pp. 108-136, 2008.

[60] E. Meyer, P. C. Abrami, C. A. Wade, O. Aslan, and L. Deault, "Improving literacy and metacognition with electronic portfolios: teaching and learning with ePEARL," Computers and Education, vol. 55, no. 1, pp. 84-91, 2010.

[61] S. C. Cartier, D. L. Butler, and N. Bouchard, "Teachers working together to foster self-regulated learning through reading by students in an elementary school located in a disadvantaged area," Psychological Test and Assessment Modeling, vol. 52, no. 4, pp. 382-418, 2010.

[62] K. R. Hilden and M. Pressley, "Self-regulation through transactional strategies instruction," Reading and Writing Quarterly, vol. 23, no. 1, pp. 51-75, 2007.

[63] N. E. Perry, "Young children's self-regulated learning and contexts that support it," Journal of Educational Psychology, vol. 90, no. 4, pp. 715-729, 1998.

[64] N. E. Perry and K. J. O. VandeKamp, "Creating classroom contexts that support young children's development of selfregulated learning," International Journal of Educational Research, vol. 33, no. 7-8, pp. 821-843, 2000.

[65] F. Perels, M. Merget-Kullmann, M. Wende, B. Schmitz, and C. Buchbinder, "Improving self-regulated learning of preschool children: evaluation of training for kindergarten teachers," British Journal of Educational Psychology, vol. 79, no. 2, pp. 311-327, 2009.

[66] B. Kramarski and T. Michalsky, "Three metacognitive approaches to training pre-service teachers in different learning phases of technological pedagogical content knowledge," Educational Research and Evaluation, vol. 15, no. 5, pp. 465485, 2009.

[67] K. Lombaerts, N. Engels, and J. van Braak, "Determinants of teachers' recognitions of self-regulated learning practices in elementary education," Journal of Educational Research, vol. 102, no. 3, pp. 163-173, 2009.

[68] Y. S. Hwang and K. Vrongistinos, "Elementary in-service teachers' self-regulated learning strategies related to their academic achievements," Journal of Instructional Psychology, vol. 29, no. 3, pp. 147-154, 2002.

[69] D. S. Davis and C. Neitzel, "A self-regulated learning perspective on middle grades classroom assessment," Journal of Educational Research, vol. 104, no. 3, pp. 202-215, 2011.
[70] C. Sugrue, "Student teachers' lay theories and teaching identities: their implications for professional development," European Journal of Teacher Education, vol. 20, no. 3, pp. 213225, 1997.

[71] N. Barnes, "The fabric of a student's life and thought: practicing cultural anthropology in the classroom," Anthropology \& Education Quarterly, vol. 23, no. 2, pp. 145-159, 1992.

[72] C. Clark and P. Peterson, "Teachers' thought processes," in Handbook of Research on Teaching, M. Wittrock, Ed., Macmillan, New York, NY, USA, 1986.

[73] N. H. Kang and C. S. Wallace, "Secondary science teachers' use of laboratory activities: linking epistemological beliefs, goals, and practices," Science Education, vol. 89, no. 1, pp. 140-165, 2005.

[74] K. E. Levitt, "An analysis of elementary teachers' beliefs regarding the teaching and learning of science," Science Education, vol. 86, pp. 1-22, 2001.

[75] M. Poulou and B. Norwich, “Teachers' causal attributions, cognitive, emotional and behavioural responses to students with emotional and behavioural difficulties," British Journal of Educational Psychology, vol. 70, no. 4, pp. 559-581, 2000.

[76] R. H. Brunning, G. J. Schraw, M. M. Norby, and R. R. Ronning, Cognitive Psychology and Instruction, Merril Prentice Hall, Upper Saddle River, NJ, USA, 2004.

[77] P. Pintrich, D. F. Smith, T. Garcia, and W. J. McKeachie, "The manual for the use of the motivated strategies for learning questionnaire (MSLQ)," Tech. Rep. 91-B-004, University of Michigan, School of Education, Ann Arbor, Mich, USA, 1991.

[78] Z. Arsal, "The effects of diaries on self-regulation strategies of preservice science teachers," International Journal of Environmental and Science Education, vol. 5, no. 1, pp. 85-103, 2010.

[79] N. E. Perry, K. O. VandeKamp, L. K. Mercer, and C. J. Nordby, "Investigating teacher-student interactions that foster selfregulated learning," Educational Psychologist, vol. 37, no. 1, pp. 5-15, 2002.

[80] R. Azevedo, "Computer environments as metacognitive tools for enhancing learning," Educational Psychologist, vol. 40, no. 4, pp. 193-197, 2005.

[81] P. H. Winne, "A perspective on state-of-the-art research on self-regulated learning," Instructional Science, vol. 33, no. 56, pp. 559-565, 2005.

[82] P. H. Winne and D. Jamieson-Noel, "Self-regulating studying by objectives for learning: students' reports compared to a model," Contemporary Educational Psychology, vol. 28, no. 3, pp. 259-276, 2003.

[83] R. Azevedo, "Theoretical, conceptual, methodological, and instructional issues in research on metacognition and selfregulated learning: a discussion," Metacognition and Learning, vol. 4, no. 1, pp. 87-95, 2009.

[84] R. Azevedo and J. G. Cromley, "Does training on selfregulated learning facilitate students' learning with hypermedia?" Journal of Educational Psychology, vol. 96, no. 3, pp. 523-535, 2004.

[85] K. A. Ericsson, "Protocol analysis and expert thought: concurrent verbalizations of thinking during experts' performance on representative tasks," in The Cambridge Handbook of Expertise and Expert Performance, K. A. Ericsson, N. Charness, R. R. Hoffman, and P. J. Feltovich, Eds., pp. 223242, Cambridge University Press, Cambridge, Mass, USA, 2006. 
[86] K. A. Ericsson and H. A. Simon, Protocol Analysis: Verbal Reports As Data, MIT Press, Cambridge, Mass, USA, 2nd edition, 1994.

[87] A. Newell and H. A. Simon, Human Problem Solving, Prentice-Hall, Englewood Cliffs, NJ, USA, 1972.

[88] J. R. Anderson, "Methodologies for studying human knowledge," Behavioral and Brain Sciences, vol. 10, no. 3, pp. 467505, 1987.

[89] M. J. Dreher and J. T. Guthrie, "Preface," Contemporary Educational Psychology, vol. 18, no. 2, pp. 127-128, 1993.

[90] M. Pressley and P. Afflerbach, Verbal Protocols of Reading: The Nature of Constructively Responsive Reading, Erlbaum, Hillsdale, NJ, USA, 1995.

[91] G. Deffner, "Interaction of thinking aloud, solution strategies and task characteristics? An experimental test of the Ericsson and Simon model," Spracher und Kognition, vol. 9, pp. 98$111,1989$.

[92] M. Heydemann, "The relation between eye-moveness and think aloud for Raven matrices," Psychologische Beitrage, vol. 28, pp. 76-87, 1986.

[93] D. Rhenius and M. Heydemann, "Think aloud during the administration of Raven's matrices," Zeitschrift fur Experimentelle und Angewandte Psychologie, vol. 76, pp. 308-327, 1984.

[94] J. A. Greene, "Collegiate faculty expectations regarding students' epistemic and ontological cognition and the likelihood of academic success," Contemporary Educational Psychology, vol. 34, no. 3, pp. 230-239, 2009.

[95] J. A. Greene, J. Torney-Purta, and R. Azevedo, "Empirical evidence regarding relations among a model of epistemic and ontological cognition, academic performance, and educational level," Journal of Educational Psychology, vol. 102, no. 1, pp. 234-255, 2010.

[96] L. Olafson and G. Shraw, "Beyond epistemology: assessing teachers' epistomolohical and ontological worldviews," in Personal Epistemology in the Classroom: Theory, Research, and Implications for Practice, L. D. Bendixen, Feucht, and F. C, Eds., pp. 516-551, Cambridge University Press, New York, NY, USA, 2010.

[97] M. A. Schommer, "Effects of beliefs about the nature of knowledge on comprehension," Journal of Educational Psychology, vol. 82, no. 3, pp. 498-504, 1990.

[98] M. A. Schommer, "Epistemological development and academic performance among secondary students," Journal of Educational Psychology, vol. 85, no. 3, pp. 406-411, 1993.

[99] M. A. Schommer, "Comparisons of beliefs about the nature of knowledge and learning among postsecondary students," Research in Higher Education, vol. 34, no. 3, pp. 355-370, 1993.

[100] R. Clark, Building Expertise: Cognitive Methods for Training and Performance Improvement, International Society for Performance Improvement, Silver Spring, Md, USA, 2008. 


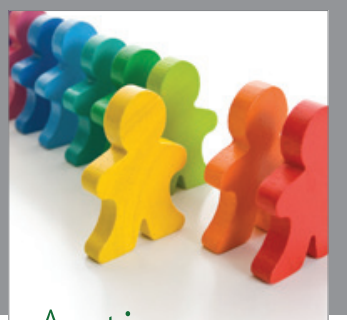

Autism

Research and Treatment
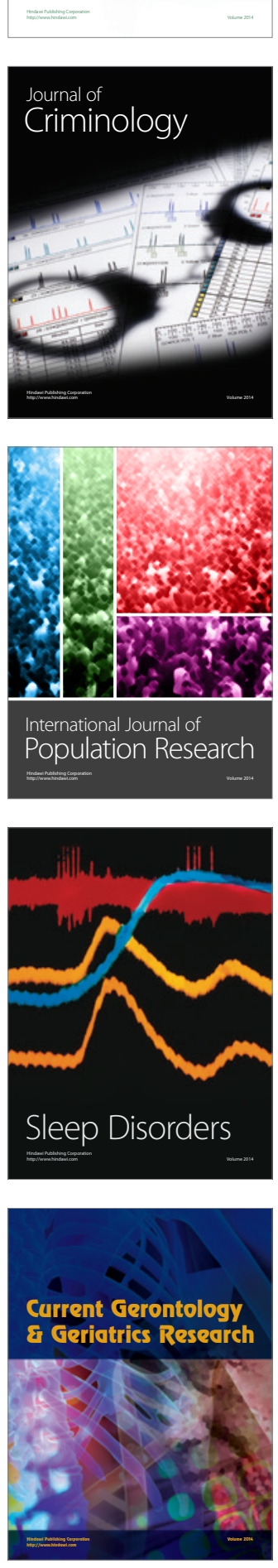
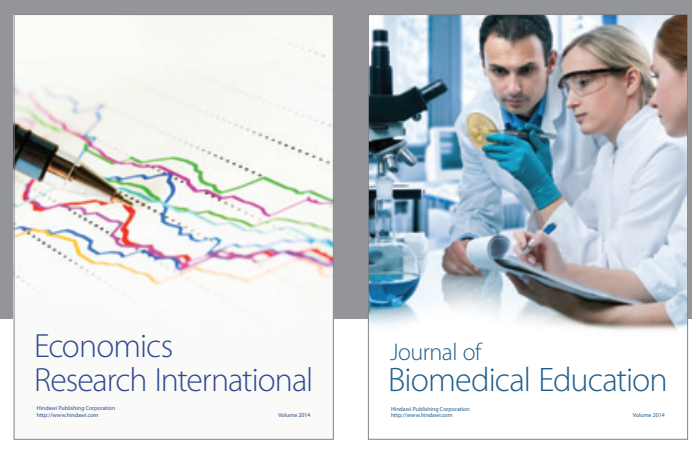

Journal of

Biomedical Education

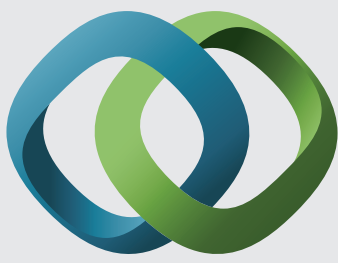

\section{Hindawi}

Submit your manuscripts at

http://www.hindawi.com
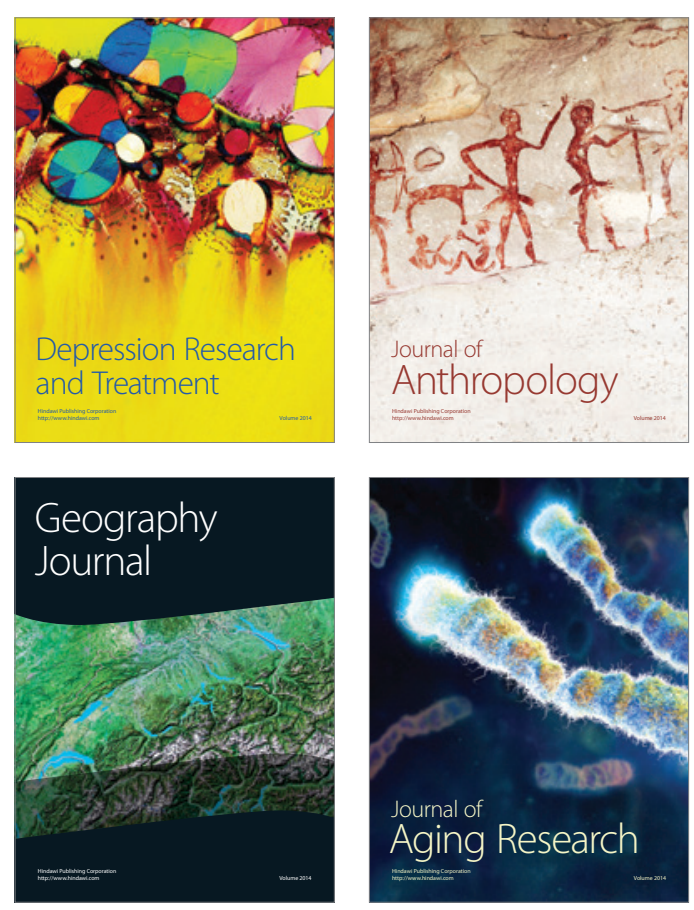

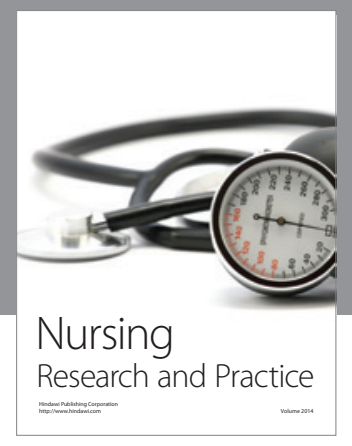

Nursing

Research and Practice

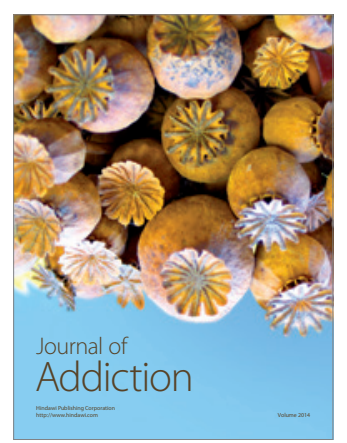

Child Development

Research

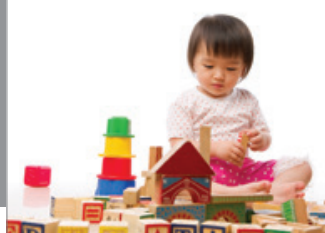

迥
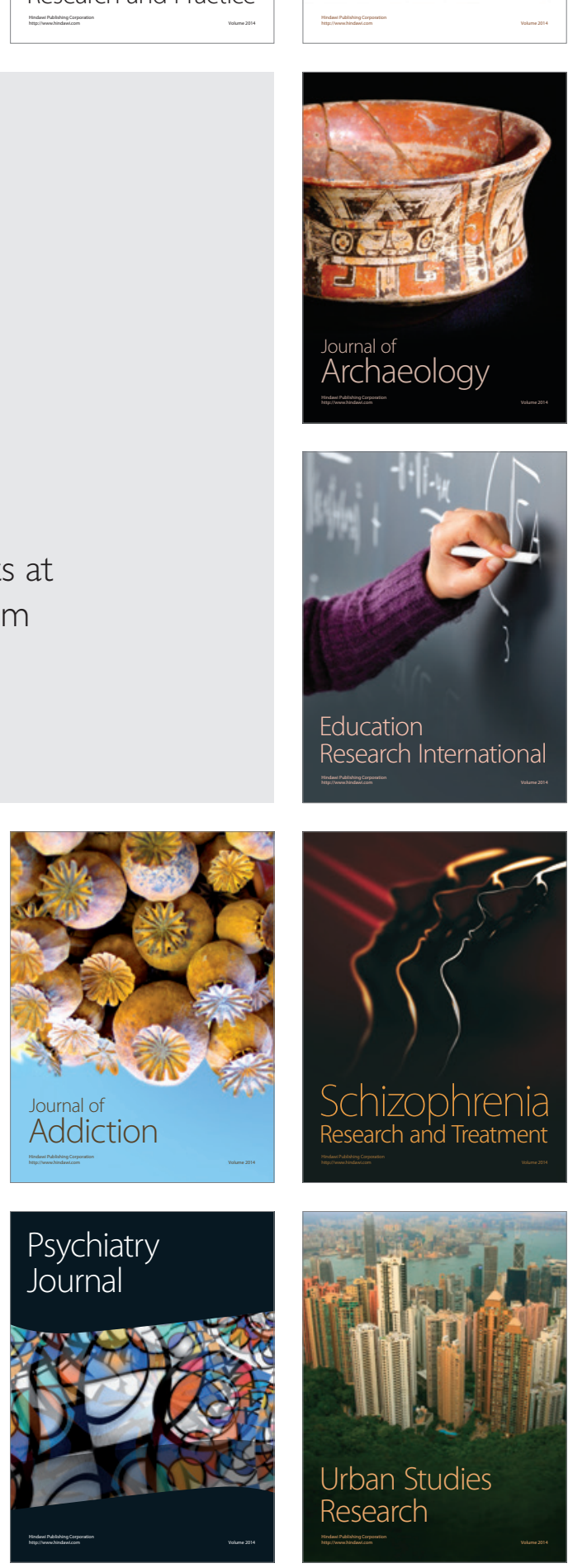